\title{
Mathematical Modeling of Hydrophysical Properties of Soils in Engineering and Reclamation Surveys
}

\author{
Vitaly Terleev ${ }^{1}$, Ekaterina Petrovskaia ${ }^{1, a}$, Natalia Sokolova ${ }^{1}$, Anastasiia Dashkina ${ }^{1}$, Inna Guseva ${ }^{1}$, \\ Vladimir Badenko ${ }^{1}$, Yulia Volkova ${ }^{1}$, Olga Skvortsova ${ }^{1}$, Olga Nikonova $^{1}$, Sergey Pavlov ${ }^{1}$, \\ Aleksandr Nikonorov ${ }^{1}$, Vitaly Garmanov ${ }^{2}$ and Wilfried Mirschel ${ }^{3}$ \\ ${ }^{1}$ Peter the Great St.Petersburg Polytechnic University, Polytechnicheskaya, 29, St. Petersburg, 195251, Russia \\ ${ }^{2}$ St.Petersburg State Agrarian University, Peterburgskoye shosse, 2, St. Petersburg-Pushkin, 196601, Russia \\ ${ }^{3}$ Leibniz-Centre for Agricultural Landscape Research, Eberswalder Straße 84, Müncheberg, 15374 Germany
}

\begin{abstract}
All structures are built of, or through, or supported by earth materials including soil. Thus soil surveys in civil-engineering field are an important step in the construction. A lot of things depend on their results, especially the cost of construction, durability. The hydraulic conductivity needs one of the most laborious, and expensive surveys, thereby it is necessary to reduce these disadvantages. Were considered different methods (a laboratory, field and a mathematical model), and conclusions were drawn about economic feasibility of using the least laborious method. This method can be used under the various constructions, when engineering or reclamation surveys take place.
\end{abstract}

\section{Introduction}

Soil surveys are an important part of construction, because the cost of construction, durability and strength of structures depends on the results of these surveys. This is especially urgent in the design of complex structures erected in dense urban areas, or to previously unexplored territories. The lack of reliable methods for predicting the effects of human impact has led to negative results (soil consolidation, degradation, and so forth). Also, a significant problem is the high labor intensity of the survey work to determine the hydraulic conductivity of the soil [1-4]. One such property is the hydraulic conductivity. There are various methods for determining the hydraulic conductivity of the soil: a laboratory, field and a mathematical model. All existing laboratory methods for measuring coefficient of hydraulic conductivity of soil can be grouped into two major groups: the first includes methods for the analysis of stationary flows of moisture in the soil, wherein the moisture and capacity distribution throughout the system, as well as the flux density in any profile of the system perpendicular to the direction of flow, are not time dependent; the second group-methods of analysis of unsteady flows, i.e., flows, in which the distribution of humidity, density and capacity changes over time and space.

Field methods of the determination of the coefficient of hydraulic conductivity involve the formation of a stationary flow of moisture at constant soil moisture. For these purposes designed soil infiltrometers, which allow providing water to the soil surface at a negative pressure so that the flow of moisture in the soil is determined not hydrohead, but the suction force of the soil. A significant

\footnotetext{
${ }^{a}$ Corresponding author : kate-petro@yandex.ru
} 
disadvantage is that in both methods the character of current and flux density are significantly different, which may affect the value of the coefficient of hydraulic conductivity.

On the basis of existing theoretical concepts, using data obtained in a few, but in a certain way planned and ordered full-scale experiments, formulates equations that describe the patterns of interaction of the elements forming the system under study, with each other and with the environment. These equations are summarized in a single system, form a mathematical (simulation) model.

Mathematical models allow solving a wide range of tasks, for example to predict the dynamics of soil moisture and groundwater level changes, as well as deformation of soils during construction and operation. Mathematical modeling of hydrophysical properties of soils enables the use of computer for the experiments, which have several advantages [5-7]: for example, to perform these experiments do not require much labour and time, while laboratory studies often involves a labour-intensive field experiments with a large number of replicates. Adequate mathematical models allow investigating the subject, even in the hypothetical circumstances [8, 9].

With regard to the problems of engineering and land reclamation surveys of particular practical importance is the opportunity to evaluate such important hydrophysical indicators such as water retention and hydraulic conductivity of soils, taking into account the hysteresis phenomenon [10-12]. In addition, the use of soil and hydrophysical model proves to be very productive in the agricultural research for precision farming technology [13], as well as a comprehensive assessment of agroreclamation systems in the planning of investments in the construction of such systems and their reconstruction [14-17].

\section{Materials and methods}

Mualem-Van Genuchten method has been used successfully for quite a long time [18, 19]. The advantages of the method are obvious. It provides an estimating the parameters of the function to interpolate the measured data of soil water retention capacity (WRC) in the form of the dependence of volumetric soil water content $\theta$ on capillary pressure of moisture $\psi$. Then these parameters are used for estimating the ratio of the hydraulic conductivity of the soil $k$ to the coefficient filtration of soil moisture $k_{\mathrm{S}}$ (relative hydraulic conductivity of the soil). The WRC model proposed by Van Genuchten is following [19]:

$$
\bar{\theta}=1 /\left[1+(-\alpha \psi)^{n}\right]^{m},
$$

where $\bar{\theta}=\left(\theta-\theta_{\mathrm{r}}\right) /\left(\theta_{\mathrm{S}}-\theta_{\mathrm{r}}\right)$ - the normalized volumetric soil moisture content; $\theta_{\mathrm{S}}$ - volumetric saturated soil moisture content; $\theta_{\mathrm{r}}$ - minimum specific volume of liquid water in the soil; $\alpha, n$ and $m$ - empirical parameters.

Van Genuchten used the formula (1) to calculate the ratio $\bar{k}=k / k_{\mathrm{S}}$ :

$$
\bar{k}=\sqrt{\bar{\theta}}\left(\int_{0}^{\bar{\theta}} d \bar{\theta} / \psi / \int_{0}^{1} d \bar{\theta} / \psi\right)^{2} .
$$

In the case $m=1-1 / n$ Eq. 2 allows a simple analytical calculation:

$$
\bar{k}=\sqrt{\bar{\theta}}\left[1-\left(1-\bar{\theta}^{1 / m}\right)^{m}\right]^{2} .
$$

The successful application of WRC (1) as an approximation of the dependence $\bar{\theta}(\psi)$ for a wide range of varieties of soil hampered by lack of physical interpretation of used soil and hydrophysical parameters. This deficiency manifests itself: firstly, the impossibility to estimate these parameters according to the indirect measurement of the physical properties of the soil; secondly, that the use of the parameters of the function approximating the relationship $\bar{\theta}(\psi)$, which obtained by interpolation of 
the experimental data in a certain range of capillary pressure, can be used to calculate $k / k_{\mathrm{S}}$ only the same range of capillary pressure.

Among the most successful attempts to overcome the above drawback relates approach proposed Kosugi $[20,21]$. The basic idea of this approach is that by integrating the Mualem's formula it is not used the dependence $\bar{\theta}(\psi)$, but normalized differential moisture capacity of the soil $\bar{\mu}=d \bar{\theta} / d \psi$, with respect to which the function $\bar{\theta}(\psi)$ describing the dependence is a primitive. Similarly with Kosugi, in author's method is based on the hypothesis of lognormal distribution of the effective radius of the soil pores is a random variable $\bar{r}=\left(r-r_{\min }\right) /\left(r_{\max }-r\right)$, where $r$ - the pore radius; $r_{\min }$ - the radius of the smallest pore and $r_{\max }$ - the radius of the largest pore. This random variable is described by lognormal distribution density functions: $f(\bar{r})=\exp \left[-1 /\left(2 \sigma^{2}\right) \ln ^{2}\left(\bar{r} / \bar{r}_{0}\right)\right] /(\bar{r} \sigma \sqrt{2 \pi})$, where $\ln \bar{r}_{0}$ - the most probable value and $\sigma$-the standard deviation of the logarithms of the effective pore radius [2022].

From Laplas' law $\psi=P-P_{a}=-\beta / r$, where $\beta=2 \gamma \cos \varphi /\left(g \rho_{\mathrm{W}}\right)$ - the coefficient of proportionality; $\gamma$ - measure the surface tension of soil moisture; $\varphi$ - angle of the contact of the surface of soil particles; $g$ - gravity acceleration; $\rho_{\mathrm{w}}$ - density of water.

During the physical modeling of desiccation of the soil, using a pneumatic press, displacement of its water is achieved from excessive pressure of atmospheric gases in the initially saturated with moisture of (without entrapped air in the pores), a soil sample, which is placed on a porous membrane. With the increase in gas pressure above the water surface in the pores of the soil from normal external atmospheric pressure $P_{a}$ to $P_{a e}$ air dissolves in water, but the water content of the pore space practically does not change and the volume of the soil moisture is maximum. The excess gas pressure is transferred to the water; the absolute pressure of water is also increased. When the excess of gas pressure reaches value $\Delta P_{a e}=P_{a e}-P_{a}$ the interaction force between water molecules and the surface of soil particles is weakened so that the water goes into the category of free gravitational water from the soil and flows through the membrane into the pan, and an empty volume of pores takes air. The excess of gas pressure in the pneumatic press relative to the external atmospheric pressure corresponds to the value of the capillary pressure of moisture in the soil of the largest pore $\psi_{a e}=-\Delta P_{a e}=-\beta / r_{\max }<0$. This value is called the bubbling pressure and is considered here as the "initial basis" of the capillary pressure of moisture. In the case of $r_{\min }<<r$ accept $r_{\min }=0$; in this case following relations are valid: $\psi-\psi_{a e}=-\beta /\left(r_{\max } \bar{r}\right)$ and $\psi_{0}-\psi_{a e}=-\beta /\left(r_{\max } \bar{r}_{0}\right)$, where $\bar{r}_{0}=r_{0} /\left(r_{\max }-r_{0}\right), r_{0}$ - the radius of the pores of the soil that corresponds to the most probable value $\ln \bar{r}_{0}$ of random variable $\ln \bar{r}$.

In [22] it has been described the $\bar{\theta}(\psi)$ approximation in the class of elementary functions:

$$
\left\{\begin{array}{l}
\bar{\theta}=\left[\begin{array}{l}
(1 / 2) \operatorname{erfc}\left\{(n \sqrt{\pi} / 4) \ln \left[-\alpha\left(\psi-\psi_{a e}\right)\right]\right\}, \psi<\psi_{a e} \\
1, \psi \geq \psi_{a e}
\end{array}\right. \\
\bar{\theta} \approx\left[\begin{array}{l}
1 /\left\{1+\left[-\alpha\left(\psi-\psi_{a e}\right)\right]^{n}\right\}, \psi<\psi_{a e} \\
1, \psi \geq \psi_{a e}
\end{array}\right.
\end{array}\right.
$$

where $\alpha=-1 /\left(\psi_{0}-\psi_{a e}\right)=r_{\max } \bar{r}_{0} / \beta$ and $n=4 /(\sigma \sqrt{2 \pi})$ - parameters. It has been described the function of the normalized differential moisture capacity of the soil:

$$
\bar{\mu}=d \bar{\theta} / d \psi=\left\{\begin{array}{l}
-(n / 4) /\left(\psi-\psi_{a e}\right) \exp \left\{-\pi(n / 4)^{2} \ln ^{2}\left[-\alpha\left(\psi-\psi_{a e}\right)\right]\right\}, \psi<\psi_{a e} ; \\
0, \psi \geq \psi_{a e} .
\end{array}\right.
$$


Thus was obtained the physically based model of differential conductivity of soil moisture. As a result the formulas that describe the ratio of the hydraulic conductivity of the soil to the coefficient of filtration of soil moisture, as well as an approximation of this ratio, are following [22]:

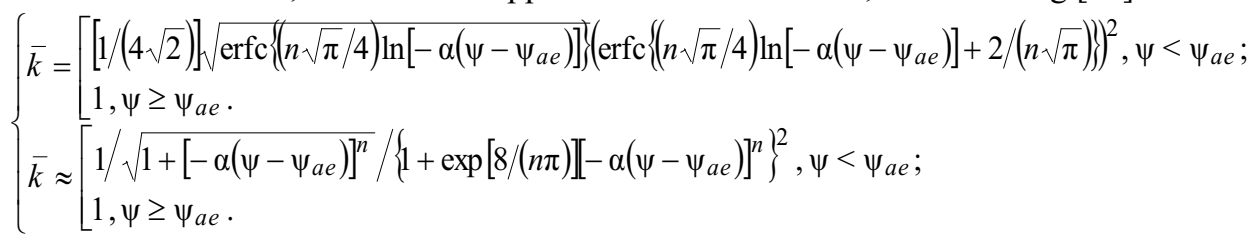

In the particular case (under $\psi_{a e}=0$ condition) formula $(6 a)$ is transformed into formula offered Kosugi [21]. Formulas (4a), (5) and (6a) form a closed system of the soil hydrophysical functions with common parameters, which are physically interpreted [23].

\section{Results and discussion}

Here is just one result of the verification of the parameters of a closed system of soil and hydrophysical functions. The data is used from the Van Genuchten's paper [19] for the clay soil Beit Netofa clay, for which Mualem-Van Genuchten method proved the least acceptable. The blue curves (1) and (2) in the fig.1 and fig.2 presents a model of Van Genuchten compared with experimental data (circles), and the red curves (3) and (4) in the fig. 1 and fig. 2 shows the results of calculation using the method described above in this paper. Visual analysis reveals much more exact coincidence of the red curves with the experimental data.

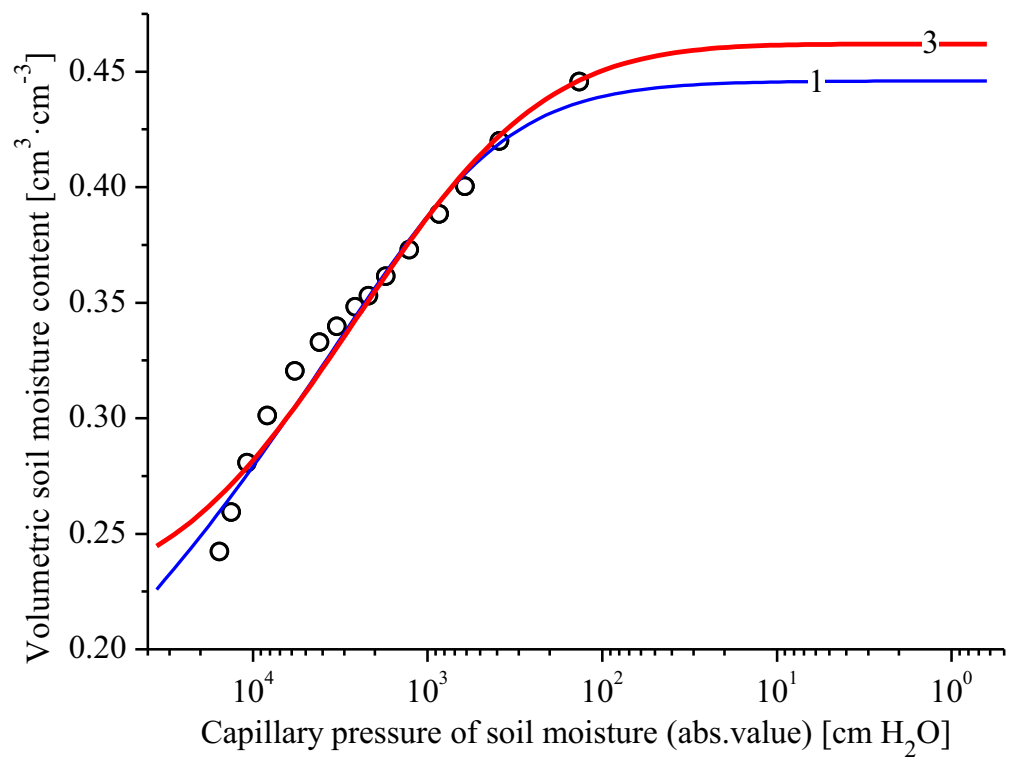

Figure 1. Water retention curve of the soil. 


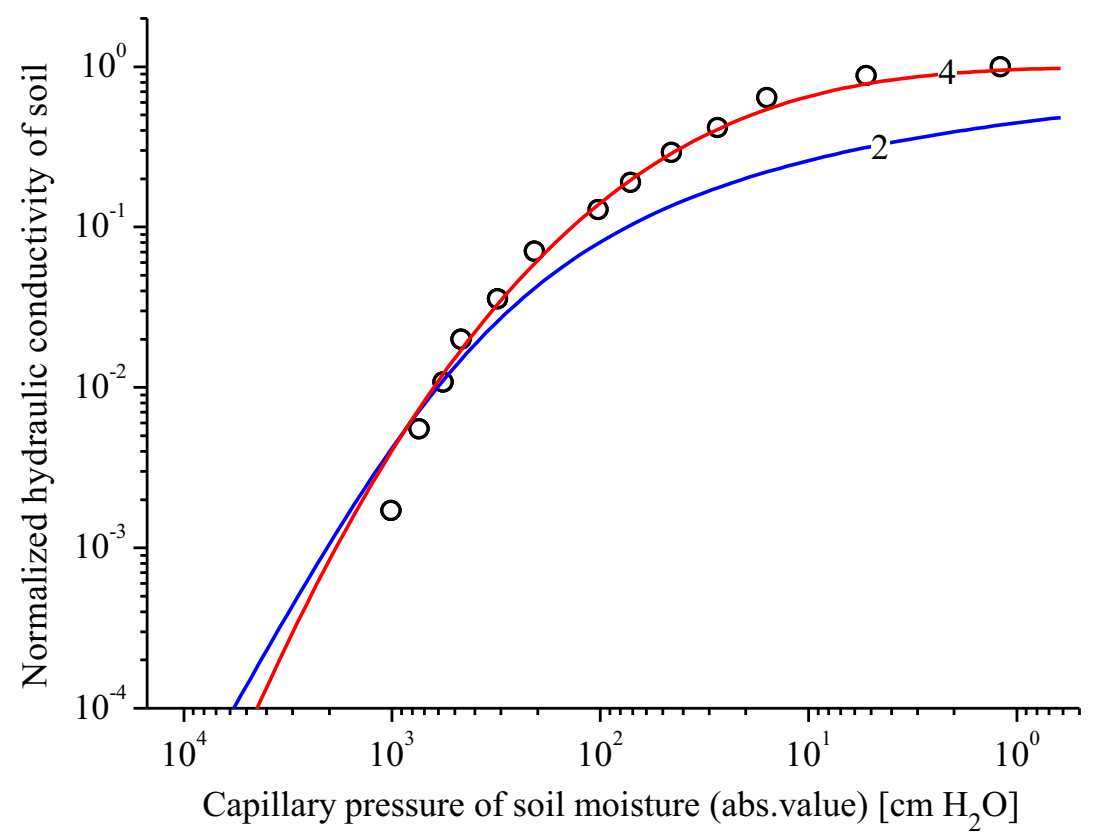

Figure 2. Normalized hydraulic conductivity of the soil.

Note that Van Genuchten predicted the hydraulic conductivity relatively accurately only in the range of capillary pressure, which is common to the soil moisture characteristic, and the hydraulic conductivity. The suggested model predicts well the hydraulic conductivity even in the range of capillary pressure, where there is no measurement of the soil moisture characteristics. It is no wonder, since the Van Genuchten's model has no physical interpretation, so it can only be an interpolation. Proposed model has a physical basis, so it has the property of extrapolation: soil moisture characteristics define parameters in a range of capillary pressure and hydraulic conductivity predicts a wider range.

Before it is not considered the economic feasibility of the use of mathematical modeling methods that are available for predicting the hydraulic conductivity of the soil according to its water-retention capacity. Direct measurement of the hydraulic conductivity of soils under laboratory conditions is very time-consuming and requires highly skilled staff. For these reasons, a small number of organizations involved in direct measurements of hydrophysical index.

The average cost of equipment, which used for measuring hydraulic conductivity of soil and fine soil is about 2000\$ [24]. Moreover, it should take into account the cost of this work (the cost of factors of production: drilling, sampling, transportation, etc.). Using the method described in [12], can significantly reduce the cost of engineering and survey works, using available data on the relative density of the addition and the density of the solid phase of the soil as well as soil texture and soilhydrological (soil hydrological) constants [10].

\section{Conclusions}

It follows that this method can find wide application because of its effectiveness and operational evaluation of a number of possibilities is very important to the reclamation construction of hydrophysical index - hydraulic conductivity of soils. This method is widely applicable under the planning preconstruction surveys, when the geological research of the landscape is done. In addition, the soil surveys are produced in landscape construction or as the part of reclamation arrangement. Soil surveys are very important, because they are the basis of all the construction [25-26]. 


\section{Acknowledgements}

The research was supported by DAAD, DFG, and Russian Foundation for Basic Research (\#16-0401473-a).

\section{References}

1. R.A. Poluektov, V.V. Terleev, Russ meteorol hydro+ 12, 73-77 (2005)

2. R. Duan, C. Fedler, J. Borrelli, J. Irrig. Drain Eng. 138, 322-327 (2012)

3. D.G. Fredlund, H. Rahardjo, M.D. Fredlund, Unsaturated Soil Mechanics in Engineering Practice (John Wiley \& Sons, 2012)

4. K.S. Perkins, Measurement and Modeling of Unsaturated Hydraulic Conductivity (INTECH Open Access Publisher, 2011)

5. R.A. Poluektov, V.V. Terleev, In: Modelling water and nutrient dynamics in soil-crop systems, 75-89 (Springer, 2007)

6. R.A. Poluektov, I.V. Oparina, V.V. Terleev, Russ meteorol hydro+ 11, 61-67 (2003)

7. R.A. Poluektov, V.V. Terleev, Russ meteorol hydro+ 11, 70-75 (2002)

8. S. Medvedev, A. Topaj, V. Badenko, V. Terleev, IFIP AICT, 448, 252-261 (2015)

9. V.V. Terleev, A.G. Topaj, W. Mirschel, Russ meteorol hydro+ 40, 278-285 (2015)

10. V.V. Terleev, W. Mirschel, U. Schindler, K.-O. Wenkel, INT AGROPHYS. 24, 381-387 (2010)

11. R.A. Poluektov, S.M. Fintushal, I.V. Oparina, D.V. Shatskikh, V.V. Terleev, E.T. Zakharova, Arch. Acker- Pfl. Boden. 48, 609-635 (2002)

12. V. Badenko, V. Terleev, A. Topaj, AMM, 635-637, 1688-1691 (2014)

13. V. Badenko, V. Terleev, N. Arefiev, J. Volkova, O. Nikonova, Proceedings of AASRI International Conference on Industrial Electronics and Applications (IEA 2015). Book Series: AER-Advances in Engineering Research, 2, 452-455 (2015)

14. N. Arefiev, V. Terleev, V. Badenko, Procedia Eng. 117, 39-44 (2015)

15. N. Arefiev. M. Mikhalev, D. Zotov, K. Zotov, N. Vatin, O. Nikonova, O. Skvortsova, S. Pavlov, T. Chashina, T. Kuchurina, V. Terleev, V. Badenko, Y. Volkova, V. Salikov, K. Strelets, M. Petrochenko, A. Rechinsky, Procedia Eng. 117, 32-38 (2015)

16. N. Arefiev, V. Badenko, A. Nikonorov, V. Terleev, Y. Volkova, Procedia Eng. 117, 20-25 (2015)

17. A. Nikonorov, S. Pavlov, V. Terleev, N. Arefiev, V. Badenko, Y. Volkova, Procedia Eng. 117, 258-263 (2015)

18. Y. Mualem, Water Resour. Res. 12, 513-522 (1976)

19. M. Th. Van Genuchten, Soil Sci. Soc. Amer. J. 44, 892-989 (1980)

20. K. Kosugi, Water Resour. Res. 30, 891-901 (1994)

21. K. Kosugi, Water Resour. Res. 32, 2697-2703 (1996)

22. V. Terleev, V. Badenko, I. Guseva, W. Mirschel, AMM, 725-726, 355-360 (2015)

23. V.V. Terleev, M.A. Narbut, A.G. Topaj, W. Mirschel, Agrofizika (Rus) 2, 35-44 (2014)

24. Information from http://www.cv.nctu.edu.tw/chinese/teacher/Ppt-pdf/AGTwk6HydraulicCon.pdf

25. R.A. Usmanov, N.I. Vatin, V.A. Murgul, AMM, 680, 474-480 (2014)

26. V. Chechevichkin, N. Vatin, AMM, 641-642, 409-415 (2014) 